\title{
LÍNGUA PORTUGUESA EM TIMOR-LESTE: FORMAÇÃO DOCENTE E PRODUÇÃO DE MATERIAL DIDÁTICO ${ }^{1}$
}

\section{IZABEL CRISTINA SILVA DINIZ}

Doutoranda em Estudos de Linguagens pelo Centro Federal de Educação Tecnológica de Minas Gerais (CEFET-MG), Belo Horizonte, BH, Brasil.

E-mail: izabel.diniz@hotmail.com

\section{MARCIA VANDINEIDE CAVALCANTE}

Doutoranda em Educação pela Faculdade de Educação da Universidade de São Paulo (FEUSP),

São Paulo, SP, Brasil.

E-mail: marciacalva@hotmail.com

\section{Resumo}

A partir da experiência como professoras de língua portuguesa (LP) em Timor-Leste, analisamos 15 unidades didáticas elaboradas por professores timorenses envolvidos no ensino de LP. Na perspectiva de compreender como se deu a elaboração dessas unidades, utilizou-se como recurso metodológico a realização de

1 Este artigo é uma versão revisada da comunicação intitulada "Unidades didáticas produzidas por professores timorenses para o PPPLE: parâmetros e perspectivas", apresentada em dezembro de 2014 no IV Congresso Internacional da AILP, em Macau, China. As autoras deste texto participaram como professoras cooperantes do Programa de Qualificação de Docentes e Ensino de Língua Portuguesa no Timor-Leste (PQLP), da Coordenação de Aperfeiçoamento de Pessoal de Nível Superior (CAPES), sob a coordenação acadêmica da Universidade Federal de Santa Catarina (UFSC). 
entrevistas semiestruturadas, envolvendo os professores-autores do referido material disponibilizado no Portal do Professor de Português Língua Estrangeira/ Língua Não Materna (PPPLE). Os resultados apontam para a importância de uma política linguística e educacional direcionada principalmente para a formação de professores no que diz respeito à elaboração de materiais didáticos de qualidade e de acordo com o contexto de ensino.

\section{Palavras-chave}

Timor-Leste. Ensino de Língua Portuguesa. Formação docente.

\section{INTRODUÇÃO}

A República Democrática de Timor-Leste é considerada um país tipicamente multilíngue. De acordo com Hull (2001), aquela pequena ilha do sudeste asiático, com pouco mais de um milhão de habitantes, apresenta atualmente em seu panorama linguístico 15 idiomas nacionais (12 austronésicos e os demais de origem papua). Nesse cenário, uma dessas línguas nacionais, o tétum, é língua oficial juntamente com o português, o qual tem importância histórica, afetiva, geoestratégica e identitária para o povo leste-timorense (COSTA, 2012; BRITO, 2010). Desde sua independência, em 2002, há um grande esforço do governo em difundir a Língua Portuguesa (LP).

Após 24 anos de domínio indonésio, o quadro de professores timorenses era deficitário, em termos quantitativos, de formação e de proficiência em português. Sendo assim, um cidadão timorense que falasse LP e que tivesse exercido cargo de professor ou que tivesse frequentado algum curso intensivo poderia se candidatar a integrante do quadro de docentes de LP. Os com maior nível de formação e melhor proficiência passaram a exercer a função de professor de português no país. Nessa fase não havia materiais didáticos da língua, ou em tétum, disponíveis, pois durante o período de ocupação da Indonésia, a língua de instrução era o Bahasa Indonésio. Dessa forma, os educadores improvisavam a partir dos poucos textos que ainda restavam do período colonial português e, principalmente, a partir dos materiais escritos pela igreja católica.

Após a chegada de professores da Cooperação Internacional Portuguesa em 2002, é que começaram a surgir os primeiros livros de ensino de português como segunda língua, contudo ainda não eram distribuídos aos educadores 
timorenses. Em 2003, foi produzido o primeiro livro específico para o ensino de português no contexto timorense a ser distribuído em larga escala, Português em Timor 1 (COIMBRA, 2003), que tem como objetivo o ensino de LP como segunda língua destinado a adultos. Esse livro, resultado da adaptação de um material produzido nos anos de 1990 para o ensino de português como língua estrangeira, passou a ser utilizado pelos professores portugueses e timorenses tanto no ensino secundário quanto nos demais cursos de LP.

Após a publicação dessa obra, vários outros materiais foram impressos pela editora portuguesa Lidel, com o objetivo do ensino da língua, tendo em vista o contexto específico de Timor (destaque para os dicionários português-tétum). A referida editora, que detinha exclusividade editorial na produção de materiais para o Ministério de Educação de Timor-Leste, produziu uma série de livros que cobria praticamente todos os níveis de ensino (cf. CARNEIRO, 2011).

O Ministério da Educação, a partir de 2012, adotou manuais didáticos para o Ensino Secundário, elaborados pela Universidade de Aveiro em Portugal. Esse material vem sendo alvo de críticas quanto à deficiência em relação à contextualização e ao nível de complexidade de alguns textos e de questões propostas. Percebe-se, portanto, que a elaboração e a publicação de livros destinados ao ensino de língua portuguesa em Timor-Leste não garantiram seu uso. Em 2012, em visita a três escolas públicas em Díli e duas em Baucau, verificamos que os livros didáticos estavam guardados em bibliotecas ou nas salas dos diretores, sob a alegação de que aquele material não correspondia à realidade timorense e também de que não havia livros suficientes para todos os alunos. Além disso, muitos professores se negaram a usar esse material didático, devido, principalmente, à dificuldade de lidar com ele e pela sua linguagem não contextualizada. Algumas iniciativas foram adotadas pelo Ministério da Educação no sentido de resolver esse problema. Uma delas foi promover cursos de capacitação aos educadores para orientá-los quanto ao uso daqueles livros didáticos.

Quando se pensa em materiais didáticos para o ensino timorense, precisa-se levar em consideração o contexto multilíngue e a cultura predominantemente oral, bem como a capacitação dos professores que atuam no ensino de LP, que, como já mencionado, mesmo após anos de independência, muitas vezes, ainda não tiveram uma formação direcionada para o ensino de português como língua não materna. 
Em 2016, o Ministério da Educação lançou novos livros didáticos elaborados por uma equipe de educadores timorense, porém ainda não se pode afirmar sobre sua aceitabilidade, já que este é o primeiro ano que estão sendo utilizados.

Tentando compreender que materiais didáticos têm sido produzidos para o ensino de português naquele contexto, selecionamos, para esta investigação, as unidades didáticas elaboradas por professores timorenses para o Portal do Professor de Português Língua Estrangeira/Língua Não Materna (PPPLE). Essa plataforma on-line oferece à comunidade de professores recursos e materiais para o ensino e a aprendizagem de Português como Língua Estrangeira (PLE). Diante disso, o presente trabalho tem por objetivo investigar os parâmetros e as perspectivas adotadas pelos educadores timorenses na produção das unidades didáticas para o referido portal. Interessa-nos conhecer como se deu o processo de elaboração desse material; como tal experiência contribuiu ou não para a prática desses professores no ensino de PLE; e se os sujeitos investigados fizeram uso desse material. Para tantos, realizamos a descrição de algumas unidades didáticas timorenses disponibilizadas no portal, bem como apresentamos as entrevistas com os professores envolvidos nessa produção. Buscamos com isso perceber quais aspectos e fatores relacionados à confecção das unidades contribuíram ou podem contribuir para a prática pedagógica de ensino de PLE em Timor-Leste.

\section{CAMINHOS TEÓRICOS}

Inserimos este trabalho em dois espaços teóricos, considerados por nós como intrínsecos, sendo eles: o campo da reflexão sobre as políticas linguísticas e o campo da reflexão sobre as políticas educacionais, especificamente, a formação do professor.

Hornberger e Ricento (1996) salientam que as pesquisas iniciais sobre políticas linguísticas, ao final de 1960 e começo de 1970, preocupavam-se com o desenvolvimento de políticas destinadas a países em processo de descolonização. Ademais, tais pesquisas visavam entender como e quais políticas poderiam contribuir para a construção de projetos de nação. No entanto, os autores ressaltam que muitos desses estudos desconsideravam o caráter político intrínseco do direcionamento que estava sendo dado às ideologias políticas. Os

80 
modelos propostos na época abarcavam os complexos parâmetros envolvidos no planejamento de políticas públicas, como se pudessem ser pensados a partir de um modelo de ciência normativa.

Dessa forma, ao final dos anos de 1980, surgiram diversas críticas, como os trabalhos de Cooper (1989) e Tollefson (1991), que ampliaram a agenda do campo para pensar as questões de política linguística articulada às teorias sociais críticas, evidenciando os conflitos sociais nas relações entre línguas/ variantes dominantes e línguas/variantes minoritárias, denunciando também os mecanismos de poder subjacentes às teorias propostas no campo, o que fez com que surgissem novos temas na área, como os direitos linguísticos.

Hornberger e Ricento (1996), embora reconheçam uma mudança significativa entre o primeiro e o segundo momento dos estudos de política linguística, enfatizam que nenhum destes tem dado conta de forma satisfatória dos processos políticos envolvidos nas camadas transnacionais, nacionais, institucionais e interpessoais que envolvem a política e o planejamento linguístico. Sobre isso, Ricento (2006) afirma que entre esses dois momentos há uma mudança de perspectivas sobre língua e sobre política linguística:

Deste modo, as teorias linguísticas adotadas pelos planejadores de políticas linguísticas, antes vistas como ferramentas científicas, objetivas e neutras passam a ser vistas por acadêmicos críticos nos anos de 1980 como prejudicial para o desenvolvimento de políticas linguísticas equitativas em contextos multilíngues complexos. Esta constatação levou a um questionamento de ideias sedimentadas sobre a natureza da linguagem e do quanto os acadêmicos da área estavam perpetuando concepções que tiveram como efeito justificar racionalmente o suporte às línguas coloniais e os interesses econômicos correlatos ao custo das línguas indígenas e do desenvolvimento econômico local ${ }^{2}$ (RICENTO, 2006, p. 14).

Diante disso, Pennycook (2006) desenha um novo quadro para o campo. Para esse autor, com o pós-modernismo sugere um número significativo de preocupações pertinentes para a política e o planejamento linguístico: primeira, questões importantes sobre como o poder opera em relação ao Estado-nação, e, em particular, como a governabilidade é alcançada por meio da língua; segunda, a ontologia da língua como um construto moderno/colonial; terceira, as grandes narrativas ou as vastas epistemologias do imperia-

2 Tradução em Carneiro (2011).

81 
lismo, dos direitos linguísticos ou do acesso à linguagem; e, por fim, quarta, as formas contingentes, contextuais, situadas e locais de entender a linguagem e as políticas linguísticas.

Ao propor esse quadro, Pennycook (2006) parte do geral para o específico, compreendendo as políticas linguísticas como um lugar de reflexão, que deve ser analisada de forma crítica em relação às noções modernas coloniais e imperialistas de nação, língua e ciência, indicando a necessidade de se entender tais políticas de um ponto de vista local, situado, contextualizado e contingente.

$\mathrm{Na}$ perspectiva das políticas educacionais, ressaltamos que a formação de um professor de língua não materna envolve uma preparação para lidar com materiais didáticos, em sentido mais restrito, textos, pois se ensina uma língua a partir de textos nela configurados. Assim, cria-se oportunidade para os aprendizes interagirem em contextos diversificados e com discursos distintos (JÚDICE, 2005).

$\mathrm{Na}$ elaboração de material didático, a seleção de textos não verbais (imagens) para atividades de leitura e de produção oral deve levar em conta: o interesse pelos aprendizes; a permeabilidade a diferentes culturas e lugares sociais; a acessibilidade dos signos não verbais e verbais; as maneiras pelas quais esses signos se articulam na construção do sentido (JÚDICE, 2005).

A escolha do material didático adotado pelo poder público também envolve questões de política pública. Assim sendo, a política linguística e educacional adotada pelos governos leste-timorenses, desde a sua independência, priorizou em um primeiro momento a capacitação de professores para usarem livros didáticos distante de sua realidade. Em um segundo momento, após uma década de independência, um grupo de educadores timorenses recebe formação para produzir material didático. Isso se deu por meio do Instituto Internacional de Língua Portuguesa e da Comunidade dos Países de Língua Portuguesa, responsáveis pelo PPPLE.

Para que se possa compreender este trabalho, apresentamos a seguir o referido portal, posteriormente, faremos a análise de 15 unidades didáticas selecionadas para abordarmos neste trabalho. Visando uma melhor compreensão de como esses materiais foram elaborados e de como estão sendo utilizados, entrevistamos quatro professores de língua portuguesa da Universidade Nacional de Timor-Lorosa'e (UNTL) e do Instituto Nacional de Formação de Docentes e Profissionais da Educação (INFORDEPE), os quais estiveram envolvidos com a elaboração do referido material. 


\section{PORTAL DO PROFESSOR DE PORTUGUÊS LÍNGUA ESTRANGEIRA/ LÍNGUA NÃO MATERNA (PPPLE)}

O PPPLE 3 é uma plataforma on-line, cujo objetivo primordial é oferecer à comunidade de professores e interessados em geral, recursos e materiais didáticos para o ensino e a aprendizagem do português como língua estrangeira. $\mathrm{O}$ referido portal foi

[...] concebido, desenvolvido, alimentado e gerido de forma multilateral, funcionando como instrumento de cooperação linguístico-cultural entre os Estados Membros da Comunidade de Países de Língua Portuguesa (CPLP). Desse modo, o PPPLE terá um papel muito importante para as estratégias de promoção, difusão e projeção do português no mundo, criando um sistema internacionalizado de gestão do ensino de PLE. (PPPLE, 2014).

Os materiais didáticos são disponibilizados gratuitamente no portal. Além de uma considerável quantidade de Unidades Didáticas (UDs) disponibilizadas para download, fato que possibilita recortes e adaptações nesse material de acordo com o planejamento do professor, o portal conta ainda com um campo de orientações e sugestões nomeado "conversa com o professor”, o qual se constitui em um espaço dialógico com reflexões sobre o ensino de PLE e com sugestões/recomendações para o trabalho cotidiano com as UDs.

Assinalamos que o PPPLE é um recurso virtual que possibilita diálogo entre os professores dos diferentes países de LP, contribuindo, assim, para a troca não apenas de material didático, como também para estabelecer um ambiente de conhecimento de usos da língua, respeitando as culturas e as variedades socioculturais de cada país da Comunidade de Países de Língua Portuguesa (CPLP): Angola, Brasil, Cabo Verde, Guiné-Bissau, Guiné Equatorial, Moçambique, Portugal, São Tomé e Príncipe e Timor-Leste.

No PPPLE, as UDs são organizadas em três níveis de proficiência, sendo eles:

3 Disponível em: <http://www.ppple.org>. Acesso em: 9 nov. 2014. 
Quadro 1 - Descritores de nível de proficiência adotado pelo PPPLE

\begin{tabular}{c|l} 
Nível 1 & $\begin{array}{l}\text { O aluno evidencia um domínio operacional limitado da língua portuguesa, } \\
\text { demonstrando ser capaz de compreender e produzir textos de gêneros e } \\
\text { temas limitados, em contextos conhecidos. Trata-se de alguém, portanto, que } \\
\text { usa estruturas simples da língua e vocabulário reduzido, interagindo em situa- } \\
\text { ções limitadas e em contextos socioculturais restritos. } \\
\text { O aluno evidencia um domínio operacional parcial da língua portuguesa, } \\
\text { demonstrando ser capaz de compreender e produzir textos de variados } \\
\text { gêneros e temas relativamente diversos, em contextos conhecidos e em } \\
\text { alguns desconhecidos, em situações simples e em algumas relativamente } \\
\text { mais complexas. Trata-se de alguém, portanto, que usa estruturas simples e } \\
\text { algumas complexas e vocabulário adequado a contextos conhecidos e a } \\
\text { alguns desconhecidos, interagindo em diferentes contextos socioculturais. }\end{array}$ \\
\hline Nível 3 & $\begin{array}{l}\text { O aluno evidencia domínio operacional amplo da língua portuguesa, demons- } \\
\text { trando ser capaz de compreender e produzir, de forma fluente, textos de } \\
\text { gêneros e temas diversos, em situações de uso conhecidas e desconhecidas, } \\
\text { simples e complexas. Trata-se de alguém, portanto, que usa estruturas com- } \\
\text { plexas da língua e vocabulário adequado e amplo, interagindo com desenvol- } \\
\text { tura nas mais variadas situações que exigem domínio da língua-alvo e em } \\
\text { diferentes contextos socioculturais. }\end{array}$
\end{tabular}

Fonte: PPPLE, 2014.

Por meio desses descritores, o professor pode optar por qual UD utilizar. No entanto, o portal alerta para o fato de que essa divisão está sendo ajustada e, portanto, é passível de alteração de acordo com as experiências dos professores. A reestruturação ou alteração dos níveis propostos dependerá do uso do material e de discussões posteriores.

Uma particularidade do portal que nos chama a atenção é a concepção de língua/linguagem adotada, ela é concebida como atividade social, sendo os contextos nos quais a língua emerge essenciais para a comunicação, ou seja, uma concepção de uso efetivo da língua. "Aprender uma língua implica usá-la nas mais variadas situações de comunicação" (PPPLE, 2014). Dessa forma, todo o sentido é construído pelos participantes na interação de modo dialético.

A relação entre língua-cultura e o seu entendimento como instância fundamental para o desenvolvimento de um processo intercultural de ensino/aprendizagem de línguas significa considerar que as experiências de trabalho com a língua em uso serão sempre ações situadas, relacionadas a eventos e contextos reais de vivência dos interlocutores. [...] quando ensinamos e aprendemos o português, estamos tratando de uma dimensão muito maior do que um conjun- 
to de formas e suas regras de combinação, mas de um modo de ser e de viver através da linguagem (PPPLE, 2014).

Nessa perspectiva, o portal destaca como relevante a relação entre língua e cultura, instância fundamental para o desenvolvimento de um processo intercultural de ensino e de aprendizagem de língua. Assim, as aulas devem valorizar os contextos reais de vivência dos interlocutores e suas negociações culturais.

\section{ANÁLISE DOS DADOS}

As UDs, um dos objetos de pesquisa deste estudo, são atividades organizadas por níveis de proficiência com tempo de duração aproximado de duas horas, trabalham questões referentes ao desenvolvimento da leitura, da escrita, da oralidade e da análise linguística. Para alcançar os objetivos propostos, selecionamos as 15 UDs do nível de proficiência $1^{4}(\mathrm{~N} 1)$ disponibilizadas na plataforma PPPLE. Cada UD é organizada em oito segmentos, sendo: unidade/

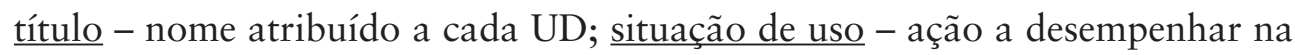
língua alvo; marcadores - palavras-chave relacionadas à unidade; expectativas

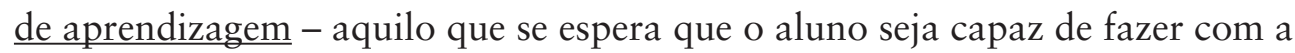
língua; atividade de preparação - momento de sensibilização e levantamento de conhecimentos prévios; bloco de atividades - conjunto de experiências de uso da língua que visa alcançar as expectativas de aprendizagem; extensão da unidade - atividades que complementam as ações de linguagens trabalhadas na unidade; e, por fim, atividade de avaliação - atividades que visam avaliar a aprendizagem do estudante.

As UDs timorenses do N1 levam os seguintes nomes: ${ }^{5} 1$. A lenda da salvação do pobre menino; 2. A lenda do Céu e da Terra ligados; 3. Carnaval; 4. Compras; 5. Compras para a festa; 6. Cuidar da saúde; 7. Danças tradicionais timorenses; 8. Da Terra ao Céu; 9. Futebol tradicional timorense; 10. Habitação tradicional timorense; 11 . No consultório; 12 . Olá, como está?; 13. Produtos timorenses; 14. Tata-Mailau; 15. Tipos de Tétum (grifo nosso).

4 Dados coletados em 22 de setembro de 2014. Nessa data, o referido portal continha no Nível de proficiência 1 - 15 UDs, no Nível 2-16 UDs e no Nível 3 - 21 UDs. Totalizando 52 UDs timorenses.

5 Optamos por apresentar as UDs em ordem alfabética.

85 
Por meio de uma observação cuidadosa desses títulos podemos levantar algumas considerações. No conjunto de UDs apresentado acima, a palavra "tradicional" ocorre três vezes; a palavra "timorense", quatro; "lendas", duas; e temas próprios da cultura e das línguas nacionais daquele país, pelo menos, duas vezes, por exemplo, "Tétum" e "Tata-Mailau". Por sua vez, os nomes atribuídos às UDs destinadas aos temas "carnaval”, "compras" e "saúde" não apresentam, no título, nenhuma marcação linguística que as vinculem especificamente a Timor-Leste. Dessa maneira podemos afirmar que os títulos das UDs analisadas podem ser classificados em duas categorias: uma que menciona algum termo próprio do universo cultural timorense e a outra categoria é a de títulos mais genéricos, relevando que esse aspecto não interfere na qualidade e riqueza do material.

Interessante observar, ainda no título das unidades, que, em todas as ocorrências, a palavra "tradicional” está vinculada à palavra timorense. A nosso ver, prezar pela tradição é um traço marcante das culturas de Timor-Leste. Conforme observou Mattoso (2001, p. 10):

[...] parecem-me, com efeito, ser específico da realidade timorense como tal, e não apenas como consequências da preservação até um período recente, de estruturas sociais que se podem classificar como «tradicionais» (...) as estruturas tradicionais marcam, evidentemente, a mentalidade dos Timorenses, e é preciso, tê-las em conta [...].

Desse modo, temos em três das 15 UDs os termos "tradicional" e "timorense" explicitamente relacionados.

Em todas as UDs selecionadas para esta investigação foram propostas leituras de imagens, ${ }^{6}$ principalmente na seção "Atividade de preparação". Essas imagens sempre estão relacionadas ao texto a ser estudado na sequência, dentro do "Bloco de atividades". Dessa forma, tem-se uma preparação, levantamento de conhecimentos prévios, para a leitura do texto a ser trabalhado no bloco seguinte. Essa estrutura demonstra coerência e interface entre as atividades de Preparação e as do Bloco.

Os textos escritos são trabalhados, nas UDs, principalmente em atividades de leitura e de análise linguística. No entanto, não encontramos nenhuma atividade que explorasse o gênero textual como processo e produto de comu-

6 Neste trabalho não contabilizamos as fotografias que constituem as UDs. 
nicação social. O que, a nosso ver, ficaria a cargo do professor enquanto sujeito responsável pelo ensino de uma determinada língua. Outro dado que nos parece relevante é o fato de que grande parte das atividades propostas nas UDs do N1 serem destinadas à leitura e à produção oral, em comparação às atividades de produção textual escrita, ocorrendo com menos frequência as tarefas comunicativas $^{7}$ nessa modalidade. As atividades de escrita raramente contemplam produção textual. Verificamos um predomínio de atividades de pergunta e resposta. O que talvez seja indício de traços da cultura majoritariamente oral existente em Timor (SILVA, 2012) ou ainda por ser um tipo de atividade mais comum na prática pedagógica daqueles professores e alunos.

Destacamos que no caso das sociedades lestes-timorenses, aplica-se, à sua obra literária predominante oral, a ideia de Rosário (1989, p. 47) de que "a tradição oral é o veículo fundamental de todos os valores, quer educacionais, quer sociais, quer político, quer culturais", as quais podem ser observadas nas lendas que dão nome a três UDs: A lenda da salvação do pobre menino; A lenda do Céu e da Terra ligados; Da Terra ao Céu. O fato de em 15 unidades encontramos três lendas timorenses demonstra o quanto questões relacionadas às culturas locais têm importância para os professores timorenses que elaboraram o material. Pressupõe-se, portanto, que essa temática despertará o interesse dos estudantes timorenses que forem utilizar o material. Esse pode ser um dos aspectos de maior diferencial entre as UDs e os demais materiais didáticos que vêm sendo utilizados ao longo do tempo em Timor-Leste, que de modo geral trazia sempre aspectos relacionados a outras culturas, deixando à margem os aspectos culturais timorenses.

Ressaltamos que alguns textos foram produzidos exclusivamente para compor as UDs e outros, a grande parte, são materiais autênticos (KRAMSCH, 1993).

A unidade "Futebol tradicional timorense" é a única, dentre as analisadas, que não traz texto na linguagem verbal, localizado no Bloco de atividades. Consideramos que o tema é bastante apropriado, levando em consideração a apreciação desse esporte por parte dos timorenses. Nessa unidade, mais duas questões nos chamaram a atenção, a primeira é o fato do título indicar um pertencimento do futebol à cultura timorense, contudo as imagens apresentadas são de crianças estrangeiras, gerando uma contradição entre o nome da

7 Tarefa é um convite para agir no mundo, um convite para o uso da linguagem com um propósito social. (BRASIL, 2006). 
unidade e as fotografias selecionadas. A segunda questão observada é a que o único gênero textual, o anúncio de uma partida de futebol entre a seleção de Timor-Leste e a seleção de Nepal, está localizado na seção Extensão da unidade, pois o mesmo não ocorre nas demais UDs, o que não infere um valor negativo, mas sim diferenciado à estrutura das outras unidades analisadas.

O fato de algumas imagens não estarem adequadas às unidades foi justificado de forma unânime no decorrer das entrevistas realizadas com os professores, pois eles afirmaram que não tiveram tempo suficiente para selecionar ou fotografar situações mais apropriadas para compor o material.

Dentre as unidades investigadas "Compras" e "No consultório" foram as que deram menos ênfase a elementos relacionados à cultura timorense, seguidas de "Futebol tradicional timorense" e "Olá, como estás?”. Já a UD "Carnaval” apresenta-se totalmente vinculada à cultura do país, uma vez que expõe imagens de crianças timorenses e de autoridades locais comemorando a data, além de exibir uma notícia sobre a realização do evento na capital, Díli. No entanto, talvez, poderia ser acrescentado ao título algum termo que caracterizasse o carnaval naquele contexto, como "Carnaval timorense" ou "Carnaval em Timor-Leste”. Esclarecemos que o título reduzido não prejudica a qualidade do material, pois foi exatamente essa UD, citada pelos entrevistados que utilizaram o material, uma das que os alunos mais apreciam.

Ainda sobre a questão cultural, podemos encontrar na maior parte das unidades do Nível 1 aspectos culturais relacionados ao modo de vida de timorenses, principalmente por meio das imagens que as compõem. Por meio das UDs podemos inferir que o carnaval é comemorado na cidade de Díli e em algumas aldeias, sendo realizada uma festa nos moldes timorenses. Na unidade "Compras para a festa” foi possível perceber qual tipo de vestuário é comumente usado por timorenses em festas de casamento. O tais (tecido artesanal considerado com um dos símbolos culturais timorense ) é usado para fazer fato (termo em português do Brasil) e a seda para fazer blusas.

$\mathrm{Na}$ UD "Danças tradicionais timorenses", tebedai é mencionada como dança típica timorense realizada tradicionalmente durante a época de colheita e abertura de uma casa sagrada. Mais uma vez percebe-se a valorização de aspectos culturais daquele país.

O conceito de língua/linguagem que se abstrai das UDs timorenses do N1 é de processo de interação, com foco em situações reais de uso, como se observa no Exemplo 1. 
Exemplo 1 - Fragmento da UD "Danças tradicionais timorenses"

UNIDADE: Danças tradicionais timorenses/ Timor-Leste

BLOCO DE ATIVIDADES

Atividade 2: Escreva um e-mail para um amigo que mora em outro país, explicando-lhe o que é o tebe ou tebedai.

Fonte: PPPLE, 2014.

Além disso, as UDs timorenses do portal tratam língua e cultura como indissociáveis. Vale destacar que as UDs trazem atividades tanto estruturalistas quanto comunicativas.

Quanto às entrevistas, estas foram realizadas por amostragem, portanto, dos onze professores-autores, quatro foram entrevistados em momentos distintos. As entrevistas ocorreram no local de trabalho dos professores timorenses, UNTL e INFORDEPE, durante o mês de novembro do ano de 2014. Por meio da entrevista, foi possível perceber a importância desse trabalho para os autores desse material didático (UDs), tanto no sentido de valorização do conhecimento desses profissionais, quanto à relevância da oportunidade de elaborar um material contextualizado para a realidade dos alunos em foco.

Apesar de nem todos os professores entrevistados ensinarem LP, eles consideraram a experiência positiva e enriquecedora. O primeiro aspecto destacado pelos professores-autores entrevistados é que eles só passaram a conhecer o PPPLE mediante a realização do trabalho com os organizadores do Portal.

As entrevistas foram realizadas de forma semiestruturada, envolvendo questões relacionadas à elaboração e à utilização do material. Dentre os aspectos relevantes citados pelos professores durante as entrevistas podemos mencionar que:

1. Consideram que mais materiais didáticos como esses precisam ser elaborados para atender melhor as necessidades dos alunos timorenses;

2. O portal é um importante veículo para que mais pessoas conheçam Timor-Leste;

3. Apesar de os entrevistados não serem habituados a lidarem com elaboração de materiais para plataformas ou sites, todos consideraram o trabalho como um desafio positivo; 
4. Os que utilizaram as UDs, afirmaram que houve aprovação do material por parte dos alunos, contudo, algumas atividades apresentaram um grau de dificuldade para o público com o qual estavam trabalhando, dessa forma precisaram ser ajustadas;

5. Um dos professores destacou que, a partir dessa experiência, já iniciou a elaboração de outro material semelhante para ser utilizado com o público estudantil que estava trabalhando naquele momento;

6. Os entrevistados tiveram dificuldade em localizar imagens para compor as UDs. Consideramos que esse aspecto se deu, também, pelo fato do acesso à internet em Timor-Leste ser caro e limitado.

\section{CONSIDERAÇÕES FINAIS}

Ao analisar as UDs, buscamos destacar as perspectivas e parâmetros adotados na confecção desse material. Assim, diante das análises expostas, identificamos, nas unidades timorenses do N1, uma visão de língua/linguagem como atividade social, cuja interação se dá em contextos específicos. Isso significa que o aluno é levado a aprender a LP de forma contextualizada, sem desprezar aspectos culturais, sociais e históricos. Tal concepção vai ao encontro da visão de língua/linguagem adotada pelo PPPLE e reflete os avanços teóricos da ciência linguística.

Por meio de análise das unidades, é possível conhecer alguns aspectos linguísticos, culturais e sociais de Timor-Leste, como: quais vestes são usadas por timorenses em cerimônias de casamento; como se comemora o Carnaval em Timor-Leste; quais são as danças e as comidas típicas daquele país, além de vocábulos em tétum que foram incorporados ao português timorense. Tais componentes socioculturais e linguísticos são acompanhados de uma linguagem específica que difere o português leste-timorense, por exemplo, do português brasileiro. Brasileiro não usa "fato", mas sim "terno", não diz "magoei-me o braço" e sim "machuquei o braço" e não comemora Carnaval da mesma forma que os timorenses, entre outras especificidades. Portanto, língua e cultura estão entrelaçadas, sendo representadas nos diferentes contextos de interação e comunicação de cada sociedade falante de LP.

Diante do exposto, consideramos o PPPLE uma ferramenta à disposição de uma política linguística adotada pela CPLP para fortalecer a lusofonia, tendo em 
vista a LP. Vale ressaltar a importância do portal que, a nosso ver, também é uma relevante ferramenta pedagógica que contribui para a formação do professor de LP e difusão dessa língua no mundo. Destacamos, ainda, que o portal é uma fonte de amostras da LP espalhada pelo mundo. Por fim, não resta dúvida de que o PPPLE tem um papel fundamental na promoção, difusão e projeção do português, não somente no contexto da CPLP, mas, também, no mundo.

\section{Portuguese language in East Timor: teacher's formation and production of didactic material ${ }^{8}$}

\section{Abstract}

Based on our experience as Portuguese language (PL) teachers in East Timor, we analyzed 15 didactic units elaborated by Timorese teachers involved in the PL teaching. In order to understand how these units were elaborated, semi-structured interviews were used as a methodological resource, involving the teachers-authors of the material available in Portal do Professor de Português Língua Estrangeira/Língua Não Materna (PPPLE). The results point out to the importance of a linguistic and educational policy focused mainly on teacher's formation in the elaboration of quality didactic materials and in accordance with the teaching context.

\section{Keywords}

East Timor. Teaching of Portuguese language. Teacher's formation.

\section{REFERÊNCIAS}

BRASIL. Manual do candidato Celpe-Bras. Brasília, 2006. Disponível em: <http:// download.inep.gov.br/outras_acoes/celpe_bras/manual/2012/manual_examinando_ celpebras.pdf >. Acesso em: 8 nov. 2014.

8 This article is a revised version of the presentation titled "Unidades didáticas produzidas por professores timorenses para o PPPLE: parâmetros e perspectivas", presented in December, 2014 at the IV International Congress of AILP in Macao, China.

The authors of this text participated as teaching cooperators in the Programa de Qualificação de Docentes e Ensino de Língua Portuguesa no Timor-Leste (PQLP) of the Coordenação de Aperfeiçoamento de Pessoal de Nível Superior - CAPES/Brasil, under the academic coordination of UFSC. 
BRITO, R. P. Temas para a compreensão do atual quadro linguístico de Timor-Leste. Ciências \& Letras, Porto Alegre, n. 48, p. 175-194, jul./dez. 2010. Disponível em: <http://seer3.fapa.com.br/index.php/arquivos/article/view/55>. Acesso em: 6 mar. 2017.

CARNEIRO, A. Política Linguística em Timor-Leste: uma reflexão acerca dos materiais didáticos, 2011. Disponível em: <http:/www.xiconlab.eventos.dype.com.br/ resources/anais/3/1308361930_ARQUIVO_ArtigoAlanCarneiro.pdf>. Acesso em: 28 de nov. 2014.

COIMBRA, I.; COIMBRA, O. Português em Timor 1, Livro do Aluno, Lisboa: Editora Lidel, 2003.

COOPER, R. Language planning and social change. Cambridge: Cambridge University Press, 1989.

COSTA, L. A língua. Fator de identidade nacional leste-timorense. In: BASTOS, N. B. (Org.). Aspectos linguísticos, culturais e identitários. São Paulo: PUC-SP, 2012.

CUNHA, G.; DACONTI, G.; MARINHO, J. H. O texto e sua tipologia: fundamentos e aplicações. Belo Horizonte: Faculdade de Letras da UFMG, 2012.

HORNBERGER, N. H.; RICENTO, T. Unpeeling the Onion: Language Planning and Policy and the ELT Professional. Tesol Quarterly, v. 30, n. 3, p. 401-427, 1996

HULL, G. Manual de Lingua Tétum para Timor-Leste. Austrália: University of Wollongong Printery, 2001a.

HULL, G. Timor-Leste/Identidade, Lingua e Política Educacional. Tradução Maria da Graça D’Orey. Lisboa: Instituto Camões. Impressão Palmigráfica. Díli, TL, 2001 b.

JÚDICE, N. O ensino da língua e da cultura do Brasil para estrangeiros: pesquisas e ações. Niterói: Intertexto, 2005.

KRAMSCH, C. Context and culture in language teaching. Oxford: University Press, 1993.

MATTOSO, J. Sobre a Identidade de Timor Lorosa'e. Camões - Revista de Letras \& Cultura Lusófonas. Edição Timor-Lorosa'e, n.14, p. 6-13, set./jul. 2001.

PENNYCOOK, A. Postmodernism in Language Policy. In: RICENTO, T. (Ed.). An introduction to language policy: theory and method. Malden: Blackwell, 2006, p. 60-75.

PPPLE. Portal do Professor de Português Língua Estrangeira/Língua Não Materna. 2014. Disponível em: <http://www.ppple.org/>. Acesso em: 9 nov. 2014.

RICENTO, T. (Ed.). An introduction to language policy: theory and method. Malden: Blackwell, 2006. 
ROSÁRIO, J. A narrativa de expressão oral. Lisboa: ICLP, 1989.

SILVA, K. Nações desunidas: práticas da ONU e a estruturação do Estado em Timor-Leste. Belo Horizonte: Editora UFMG, 2012.

TOLLEFSON, J. W. Planning language, planning inequality. Londres: Longman, 1991.

Recebido em 14-03-2017.

Aprovado em 27-03-2017. 